Article

\title{
High Prevalence of Sarcopenia in Older Trauma Patients: A Pilot Study
}

\author{
Robert C. Stassen, Kostan W. Reisinger, Moaath Al-Ali, Martijn Poeze, Jan A. Ten Bosch $(D)$ \\ and Taco J. Blokhuis *(D) \\ Department of Traumatology, Maastricht University Medical Centre+, 6229HX Maastricht, The Netherlands; \\ robert.stassen@mumc.nl (R.C.S.); k.reisinger@zuyderland.nl (K.W.R.); moaath.alali@mumc.nl (M.A.-A.); \\ martijn.poeze@mumc.nl (M.P.); jan.ten.bosch@mumc.nl (J.A.T.B.) \\ * Correspondence: taco.blokhuis@mumc.nl
}

Received: 8 June 2020; Accepted: 27 June 2020; Published: 29 June 2020

\begin{abstract}
Sarcopenia is related to adverse outcomes in various populations. However, little is known about the prevalence of sarcopenia in polytrauma patients. Identifying the number of patients at risk of adverse outcome will increase awareness to prevent further loss of muscle mass. We utilized data from a regional prospective trauma registry of all polytrauma patients presented between 2015 and 2019 at a single level-I trauma center. Subjects were screened for availability of computed tomography (CT)-abdomen and height in order to calculate skeletal mass index, which was used to estimate sarcopenia. Additional parameters regarding clinical outcome were assessed. Univariate analysis was performed to identify parameters related adverse outcome and, if identified, entered in a multivariate regression analysis. Prevalence of sarcopenia was $33.5 \%$ in the total population but was even higher in older age groups (range 60-79 years), reaching $82 \%$ in patients over 80 years old. Sarcopenia was related to 30-day or in-hospital mortality $(p=0.032)$, as well as age $(p<0.0001)$, injury severity score $(p=0.026)$, and Charlson comorbidity index $(p=0.001)$. Log rank analysis identified sarcopenia as an independent predictor of 30-day mortality $(p=0.032)$. In conclusion, we observed a high prevalence of sarcopenia among polytrauma patients, further increasing in older patients. In addition, sarcopenia was identified as a predictor for 30-day mortality, underlining the clinical significance of identification of low muscle mass on a CT scan that is already routinely obtained in most trauma patients.
\end{abstract}

Keywords: sarcopenia; polytrauma; prevalence; mortality; skeletal mass index; muscle mass

\section{Introduction}

Sarcopenia, a disease characterized by progressive loss of skeletal muscle mass (SMM), muscle strength, and physical performance, is a common condition among senior adults [1]. It is associated with a wide range of adverse outcomes and leads to a decreased quality of life and increased mortality [1-4]. The clinical relevance of sarcopenia has been extensively described in various disorders [5-8]. In addition, the predictive value of skeletal muscle mass measurements for complications has been demonstrated in various areas of surgery, such as general, vascular, colorectal, and liver transplant surgery $[7,9,10]$.

With worldwide increased life expectancy and associated increased incidence in geriatric polytrauma patients, prevalence of sarcopenia in trauma patients is expected to increase as well [11,12]. To date, prevalence of sarcopenia in polytrauma patients is largely unknown. Evidence on adverse outcome related to sarcopenia in polytrauma patients is scarce and quality of available studies is limited [13-15]. One limiting factor is the heterogeneity in polytrauma patients, including all age groups, different trauma mechanisms and a variety in pre-existing medical conditions. In addition, use of different definitions for sarcopenia hampers the comparison of studies in trauma patients $[1,16,17]$. 
Nevertheless, on arrival of a trauma patient, a total-body computed tomography (CT) scan is obtained almost routinely, and CT-based measurement of skeletal muscle mass is the gold standard for quantification of SMM. Therefore, the abdominal CT scan offers the opportunity to identify patients with low muscle mass directly.

The aim of this pilot study was to investigate the prevalence of low muscle mass in older polytrauma patients, as well as to explore the relation between low muscle mass and mortality, complications, and inflammatory response. We hypothesize that a low skeletal muscle mass on abdominal CT, as an indicator of sarcopenia, is common in polytrauma patients of increased age and that it could aggravate their clinical outcome by increasing the risk of complications. In addition, we hypothesize that low muscle mass is a predictor of 30-day or in hospital mortality and that it induces an increased early inflammatory response during hospitalization.

\section{Patients and Methods}

Approval for this study was acknowledged by the local ethics committee of the Maastricht University Medical Centre (MUMC+, Maastricht, the Netherlands). Requirement for informed consent was waived because of the retrospective nature of this study.

\subsection{Patients and Determination of Muscle Mass}

Data from polytrauma patients (injury severity score (ISS) $\geq 16$ ) who were admitted to a single level-I trauma center between January 2015 and December 2019 were assessed for study eligibility. Patient records were retrospectively checked for presence of an abdominal CT scan and patient height. Only when both abdominal CT scan on admission and height were available, patient data were included for analysis. Measurement of SMM was performed using abdominal CT images by two independent observers using OsiriX Lite 11.0.2 open software on transverse slides of abdominal CT scan at the level of third lumbar (L3) vertebra as described before $[18,19]$. All measurements were performed in a semi-automated fashion by setting tissue of interest threshold at -30 to +110 Hounsfield Units (HU) for skeletal muscle [20]. Automatically generated areas of interest were corrected manually. Total muscle mass area was automatically calculated and displayed in square centimeters.

Skeletal mass index (SMI), a derivative of the skeletal muscle mass (SMM) [21], was then calculated using the following equation:

$$
\text { Skeletal mass Index }=\text { Skeletal muscle mass }(\mathrm{SMM}) / \text { height }^{2}
$$

To estimate prevalence of sarcopenia in the study population, sarcopenia was defined according to cutoff values for SMI as described by Prado et al. [18]. These values were determined at $52.4 \mathrm{~cm}^{2} / \mathrm{m}^{2}$ and $38.5 \mathrm{~cm}^{2} / \mathrm{m}^{2}$ for males and females, respectively. Two independent investigators measured the L3 muscle area of all patients and these data were used to calculate the interobserver agreement. Intra-observer agreement was assessed by repeating 50 L3-measurements 6 months after initial analysis.

\subsection{Clinical Outcome}

Complications were retrieved from patient data by two observers. For this purpose, complications (pneumonia, urinary tract infection, delirium and mortality (both in hospital and 30-day)) and duration of intensive care unit (ICU) admission and hospitalization were all scored. Diagnosis of pneumonia was based on chest radiographs and antibiotic treatment [22]. Urinary tract infection was defined as positive urinary culture and initiation of antibiotic therapy [23]. Delirium was diagnosed by a geriatrician in patients with altered mental status and if they received medical treatment [24]. In addition, inflammatory variables (leukocytes and C-reactive protein (CRP) on admission, after 24 and $48 \mathrm{~h}$ ) were evaluated. Data from patients with severe head trauma who deceased within $24 \mathrm{~h}$ were included in the analysis of prevalence of sarcopenia. However, their data were excluded from analysis of complications. 


\subsection{Statistical Analysis}

Frequencies are presented as absolute numbers and percentages. Continuous data is presented as mean ( \pm standard error of the mean). Normal distribution was tested using Kolmogorov-Smirnov test. Differences between groups were analyzed using Pearson $\chi^{2}$ test for dichotomous variables. Confidence intervals were calculated using logistic regression analysis. First, univariate analysis was performed to select parameters directly related to adverse outcome. Dependent variables that were identified in univariate analysis were subsequently entered into a multivariate logistic regression analysis. The influence of sarcopenia on 30-day mortality was determined using a log rank test.

The interobserver agreement (R.S., M.A.) of L3 muscle index assessment of sarcopenia was analyzed by the Pearson correlation index. Two-tailed $\mathrm{P}$ values less than 0.05 were considered significant. All statistical analyses were performed using SPSS (version 25.0; SPSS Inc. Chicago, IL, USA).

\section{Results}

\subsection{Patients}

Data from 846 polytrauma patients were assessed for eligibility. In 428 patients, no abdominal CT-scan was available. Further exclusion was due to missing data regarding patient height $(n=179)$ and death within 24 hours due to brain injury $(n=1)$. Therefore, data from 239 polytrauma patients were included in analysis of prevalence and from 238 for complications, excluding the single patient who died of severe brain injury within 24 hours. Patient demographics are listed in Table 1. One-hundred fifty nine of $239(66.5 \%)$ patients were male, and 80 of 239 (33.5\%) were female. Average age was 49 years (range 6-89, SD 21.45), with a non-significant distribution among gender $(48( \pm 20)$ and $53( \pm 24)$ years for males and females, respectively, $p=0.078)$. For the total population, the following means were observed: ISS $26.7( \pm 9.9)$, body mass index (BMI) $25.0 \mathrm{~kg} / \mathrm{m}^{2}( \pm 4.3)$, Charlson Comorbidity Index 1.7 ( \pm 2.1). Patients were hospitalized for an average of 19 days ( \pm 17$)$. Mean L3 SMI for males and females was $57.4 \mathrm{~cm}^{2} / \mathrm{m}^{2}( \pm 10.24)$ and $42.7 \mathrm{~cm}^{2} / \mathrm{m}^{2}( \pm 7.82)$, respectively.

Table 1. Patient characteristics.

\begin{tabular}{|c|c|c|c|c|c|}
\hline & No. of Patients (\%) & Mean (SD) & Sarcopenic & Non-Sarcopenic & Significance \\
\hline \multicolumn{6}{|l|}{ Gender } \\
\hline Male & $159(66.5 \%)$ & & 51 & 108 & \\
\hline Female & $80(33.5 \%)$ & & 30 & 50 & \\
\hline \multicolumn{6}{|l|}{ Age } \\
\hline Male & & $48( \pm 20)$ & $52( \pm 21.9)$ & $46( \pm 18.7)$ & $p=0.046$ \\
\hline female & & $53( \pm 24)$ & $66( \pm 22.7)$ & $46( \pm 21.0)$ & $p<0.0001$ \\
\hline$>80$ & $20(8.3 \%)$ & & & & \\
\hline Male & & $84( \pm 3)$ & 5 & 1 & \\
\hline Female & & $83( \pm 2)$ & 12 & 2 & \\
\hline \multicolumn{6}{|l|}{ BMI } \\
\hline$<18.5$ & $7(2.9 \%)$ & & $4(1.7 \%)$ & $3(5.1 \%)$ & $p=0.174$ \\
\hline $18.5-24.9$ & $120(50.5 \%)$ & & $54(22.7 \%)$ & $66(27.7 \%)$ & $p<0.0001$ \\
\hline $25-29.9$ & $88(36.9 \%)$ & & $20(8.4 \%)$ & $68(28.6 \%)$ & $p=0.006$ \\
\hline$>30$ & $23(9.7 \%)$ & & $2(0.8 \%)$ & $21(8.8 \%)$ & $p=0.005$ \\
\hline Length of hospital stay (days) & & $19( \pm 17)$ & $17.6( \pm 15.9)$ & $20.1( \pm 17.3)$ & $p=0.29$ \\
\hline Length of stay ICU (days) & & $6( \pm 8)$ & $5.4( \pm 7.5)$ & $6.2( \pm 8.6)$ & $p=0.48$ \\
\hline Injury severity score & & $26.7( \pm 9.9)$ & $25.9( \pm 9.3)$ & $27.1( \pm 10.2)$ & $p=0.34$ \\
\hline \multicolumn{6}{|l|}{ Charlson comorbidity index } \\
\hline $0-1$ & $145(60.9 \%)$ & & 37 & 108 & \\
\hline$>2$ & $94(39.9 \%)$ & & 44 & 50 & \\
\hline \multicolumn{6}{|l|}{ SMI } \\
\hline Male $<52.4$ & $52(21.8 \%)$ & & & & \\
\hline Female $<38.5$ & $30(11.8 \%)$ & & & & \\
\hline \multicolumn{6}{|l|}{ Complications } \\
\hline Pneumonia & $43(18.1 \%)$ & & $17(20.9 \%)$ & $26(16.4 \%)$ & \\
\hline Urinary tract infection & $11(5.5 \%)$ & & $2(2.5 \%)$ & $9(5.6 \%)$ & \\
\hline Delirium & $51(21.0 \%)$ & & $22(27.2 \%)$ & $29(18.4 \%)$ & \\
\hline Mortality within 1 month & $18(7.5 \%)$ & & $10(12.3 \%)$ & $8(5.1 \%)$ & $p=0.032$ \\
\hline Mortality within 1 year & $8(3.4 \%)$ & & $4(4.9 \%)$ & $4(2.5 \%)$ & \\
\hline Mortality after 1 year & $5(2.1 \%)$ & & $3(3.7 \%)$ & $2(1.3 \%)$ & \\
\hline $\begin{array}{l}\text { Number of patients requiring emergency ( }<24 \\
\text { h) surgery }\end{array}$ & $108(45.4 \%)$ & & $33(41.3 \%)$ & $75(47.5 \%)$ & \\
\hline Number of patients requiring ICU admission & $181(76.1 \%)$ & & $127(80.4 \%)$ & $54(67.5 \%)$ & \\
\hline
\end{tabular}

BMI: body mass index; SD: standard deviation; ICU: intensive care unit; SMI: skeletal mass index. 


\subsection{Prevalence}

Prevalence of sarcopenia using the criteria as defined by Prado et al. was 80 out of 239 patients $(33.5 \%)$, of whom $52(65 \%)$ were male and 28 out of $80(35 \%)$ were female (see Table 2). Mean SMI in the sarcopenic group was $42.8( \pm 6.9)$ while this was $57.5( \pm 10.5)$ for the non-sarcopenic group. SMI in males was higher compared to females $\left(57.4 \mathrm{~cm}^{2} / \mathrm{m}^{2}( \pm 10.2)\right.$ vs $42.7 \mathrm{~cm}^{2} / \mathrm{m}^{2}( \pm 7.8)$, respectively). In the older cohort ( $>80$ years), prevalence increased to $85 \%$, with an even distribution between males and females (83.3\% and $85.7 \%$, respectively). Patients defined as sarcopenic were older than non-sarcopenic patients (57 years $( \pm 22.9)$ and 46 years $( \pm 19.5)$, respectively, $p<0.0001)$. ISS was comparable in sarcopenic (ISS $=25.9$ ) and non-sarcopenic (ISS $=27.2)$ patients. The relation between age, ISS, and SMI is represented in Figure 1.

Table 2. Sarcopenia prevalence in polytrauma population.

\begin{tabular}{cccc}
\hline & General Population (\%) & Age 60-79 (\%) & Age $\geq \mathbf{8 0}(\mathbf{\%})$ \\
\hline Group & & & \\
Females & $11.8(n=28 / 239)$ & $13.6(n=9 / 66)$ & $60(n=12 / 20)$ \\
Males & $21.8(n=52 / 239)$ & $24.2(n=16 / 66)$ & $25(n=5 / 20)$ \\
\hline
\end{tabular}

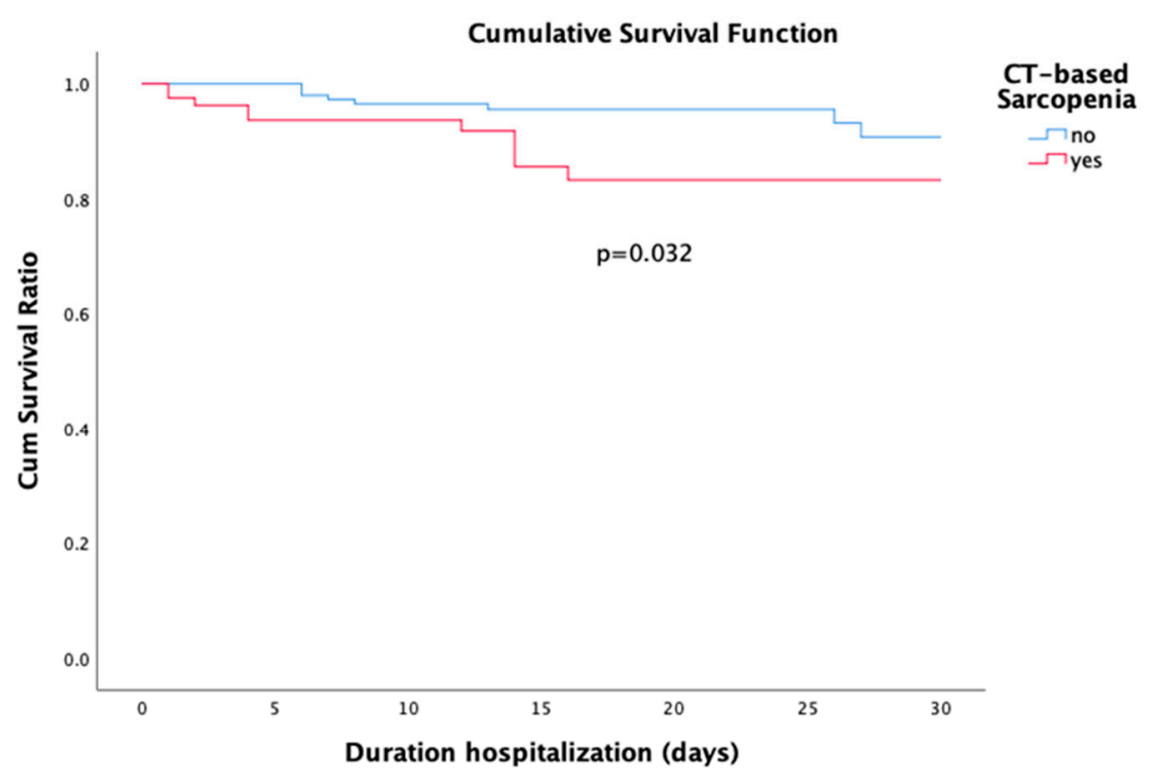

Figure 1. Survival curves for sarcopenia and no sarcopenia.

\subsection{In Hospital Mortality}

Eighteen $(7.6 \%)$ patients died within one month or during hospital admission. Log rank analysis identified sarcopenia as an independent predictor of 30-day mortality ( $p=0.032$, Figure 1$)$. In univariate analysis, sarcopenia $(p=0.045)$ was identified as a predictor for 30-day or in-hospital mortality. In addition, age $(p=0.005)$, Charlson Comorbidity Index $(p=0.001)$, ISS $(p=0.026)$, surgical procedures $(p=0.038)$, and hospital length of stay $(p=0.004)$ were significant predictors of mortality within one month. In the binary logistic regression analysis age (OR, 1.08; 95\% CI 1.01-1.165; $p=0.018)$, ISS (OR, 1.19; 95\% CI 1.04-1.20; $p=0.003$ ) and hospital length of stay (OR, $0.83 ; 95 \%$ CI $0.74-0.92$; $p<0.0001)$ remained as independent predictors of mortality within one month or during hospital admission. Logistic regression results are summarized in Table 3. 
Table 3. Logistic regression analysis of mortality within one month.

\begin{tabular}{|c|c|c|c|c|c|}
\hline & \multirow[b]{2}{*}{ Mortality } & \multicolumn{2}{|c|}{ Univariate Analysis } & \multicolumn{2}{|c|}{ Multivariate Analysis } \\
\hline & & Odds Ratio & $p$-Value & Odds Ratio & $p$-Value \\
\hline \multicolumn{6}{|l|}{ Gender } \\
\hline Male & 9/150 & 1 & & & \\
\hline Female & 9/79 & $2.14(0.82-5.6)$ & 0.115 & & \\
\hline Age & & $1.05(1.02-1.08)$ & 0.005 & & \\
\hline BMI & & $0.93(0.82-1.04)$ & 0.21 & & \\
\hline \multicolumn{6}{|l|}{ Sarcopenia } \\
\hline No & $8 / 157$ & 1 & & & \\
\hline Yes & $10 / 81$ & $2.62(0.99-6.93)$ & 0.45 & & \\
\hline Charlson Comobidity Index & & $1.46(1.20-1.77)$ & 0.001 & & \\
\hline Injury Severity Score & & $1.05(1.00-1.09)$ & 0.026 & $1.19(1.00-1.41)$ & 0.05 \\
\hline \multicolumn{6}{|l|}{ Surgery during hospitalization } \\
\hline No & & 1 & & & \\
\hline Yes & & $0.36(0.14-0.98)$ & 0.38 & & \\
\hline \multicolumn{6}{|l|}{ Inflammatory parameters } \\
\hline Plasma CRP at hospitalization & & $0.97(0.87-1.07)$ & 0.55 & & \\
\hline $\begin{array}{l}\text { Plasma Leukocyte at } \\
\text { hospitalization }\end{array}$ & & $1.01(0.98-1.03)$ & 0.59 & & \\
\hline Plasma CRP after $24 \mathrm{~h}$ & & $0.99(0.99-1.01)$ & 0.85 & & \\
\hline Plasma Leukocytes after $24 \mathrm{~h}$ & & $1.08(0.95-1.24)$ & 0.25 & & \\
\hline Plasma CRP after $48 \mathrm{~h}$ & & $0.99(0.99-1.00)$ & 0.19 & & \\
\hline Plasma leukocytes after $48 \mathrm{~h}$ & & $1.13(0.94-1.36)$ & 0.20 & $1.77(1.06-2.96)$ & 0.029 \\
\hline \multicolumn{6}{|l|}{ Complications } \\
\hline \multicolumn{6}{|l|}{ Pneumonia } \\
\hline No & $14 / 195$ & 1 & & & \\
\hline Yes & $4 / 43$ & $1.33(0.41-4.25)$ & 0.63 & & \\
\hline \multicolumn{6}{|l|}{ Urinary tract infection } \\
\hline No & $18 / 227$ & & & & \\
\hline Yes & $0 / 11$ & & 0.33 & & \\
\hline \multicolumn{6}{|l|}{ Delirium } \\
\hline No & $11 / 187$ & 1 & & & \\
\hline Yes & $7 / 51$ & $2.55(0.93-6.94)$ & 0.06 & & \\
\hline ICU length of stay & & $0.99(0.93-1.06)$ & 0.84 & & \\
\hline Hospital length of stay & & $0.89(0.82-9.63)$ & 0.004 & $0.67(0.50-0.89)$ & 0.006 \\
\hline
\end{tabular}

CRP: C-reactive protein.

\subsection{Complications and Inflammatory Response}

The incidence of complications was $68(45.3 \%)$ in non-sarcopenic patients and $41(52.6 \%)$ in sarcopenic patients $(p=0.28)$. No significant differences were observed between sarcopenic and non-sarcopenic cohorts regarding prevalence of pneumonia $(p=0.25)$, urinary tract infection $(p=0.34)$, delirium $(p=0.085)$ and ICU $(p=0.48)$ or hospital length of stay $(p=0.29)$. The inflammatory response in sarcopenic patients showed a significant increase in leukocyte levels at 48 hours compared to non-sarcopenic patients (11.95 $( \pm 3.64)$ vs $10.08( \pm 3.04)$, respectively, $p=0.002)$. The other time points (admission and 24 hours after admission) showed no difference for leukocyte levels $(p=0.18$ and $p=0.45$, respectively).

\subsection{Interobserver Agreement of CT Based Muscle Measurement by Osirix}

Interobserver agreement analysis of all measurements showed a strong and significant correlation $\left(\mathrm{R}^{2}=0.99 ; p<0.0001\right)$. The interclass correlation coefficient (ICC) of sarcopenia assessment by CT image analysis using Osirix was $0.99(p<0.0001)$ with a Cronbach alpha of 0.99 . The interobserver coefficient of variation (CV) was $10.1 \%$. Intraobserver agreement analysis of 50 L3-measurements showed a significant correlation $(0.863 ; p<0.0001)$ in the repeated measurements.

\section{Discussion}

The clinical significance of sarcopenia, defined in this study as a decreased skeletal muscle mass (SMM), is becoming evident in many fields of medicine. The depletion of muscle mass is a risk factor for infection during hospitalization in both non-cancer patients and cancer patients $[9,25,26]$. Furthermore, it has been revealed that sarcopenia in cancer patients is associated with treatment 
toxicity, poor functional status, increased length of hospital stay, prolonged rehabilitation care, and increased mortality (Huaiying 2019) [9,18,27-29]. The prevalence of sarcopenia in community-dwelling populations is up to $29 \%$, ranging from $12 \%$ to $60 \%$ in patients with colorectal cancer [30,31]. However, despite the direct clinical relevance, the prevalence of sarcopenia in polytrauma patients is unclear. This study identified a prevalence of $34 \%$ in the overall polytrauma study group, increasing to more than $80 \%$ in polytrauma patients aged over 80 years. Furthermore, our data indicate a relationship between sarcopenia and 30-day or in-hospital mortality, regardless of gender, underlining the clinical significance of sarcopenia in polytrauma patients.

Our data are in line with other studies that have described the prevalence of sarcopenia in various populations [32-34]. In general populations, von Haehling and colleagues describe a prevalence of $5-13 \%$ in people aged $60-70$ years, increasing to $11-50 \%$ in those aged 80 or above. These numbers are comparable to the prevalence of sarcopenia in populations suffering from obstructive pulmonary disease (COPD), renal failure and cancer $[5,35,36]$. The present study shows a higher prevalence of sarcopenia in polytrauma patients compared to other studies using the same age groups. Although the reason for this higher prevalence is beyond the scope of the current analysis, it raises questions on the causal relationship between sarcopenia and accidents. Sarcopenia is associated with an increased risk of falling [37], and in a part of the current population, a fall was registered as mechanism of trauma. Another aspect that has to be taken into account in interpretation of the high prevalence in our population is the applied definition of sarcopenia. In the present study, the criteria for skeletal muscle mass as described by Prado were used. Other definitions of sarcopenia use functional tests in addition to the quantification of muscle mass, such as the EWGSOP-II definition that uses hand-grip strength and gait speed [1]. However, in the polytrauma population these parameters are not readily obtainable. This limitation is mostly due to the extremity injuries frequently present in polytrauma patients, but also admission to the ICU and (prolonged) ventilation makes it impossible to obtain these data. Obtaining data during the admission is not straight forward, as loss of muscle mass and muscle function occurs within days during bedrest [38]. In contrast, a total-body CT scan is performed almost routinely upon arrival of a polytrauma patient, providing detailed imaging of the abdomen. The quantification of skeletal muscle mass is therefore readily available, and our study indicates that this parameter is directly related to survival.

The relation between sarcopenia and mortality, as indicated by many publications, appears in the univariate analysis of our data as well. In addition, a clear prediction of 30-day mortality was found. The identification of sarcopenia in these analyses is in line with available literature, showing increased mortality within one year of diagnosing sarcopenia $[39,40]$. A recent study by Leeper et al. indicates sarcopenia to be a strong predictor of 6-month post-discharge mortality in elderly trauma patients [41]. However, in the multivariate analysis in our study, we were unable to maintain sarcopenia as an independent risk factor for 30-day or in-hospital mortality. This is likely due to the small sample size in our study, as well as the stronger correlation between mortality and other factors such as age and trauma severity. Notwithstanding this effect, in the study by Leeper et al., an association is described between mortality and a variety of factors including ICU and hospital length of stay and injury scoring systems like Injury Severity Score and Abbreviated Injury Scale. Our data are in accordance with their findings.

Obtaining an abdominal CT scan is becoming a more and more widespread routine in trauma patients [42]. Our data showed the same trend, as the percentage of patients excluded for missing CT data decreased per year. Surprisingly, data from routinely obtained trauma CT scans are only seldom used for muscle mass measurement in clinical practice. We believe that the addition of skeletal mass measurement analysis in trauma patients has a direct beneficial effect, since treatment of low muscle mass can be initiated immediately, and further loss of muscle mass could be prevented. One consideration in using only CT derived data is, however, the mentioned cutoff values for the L3 index, which are used to estimate sarcopenia. As these values are based on obese patients with cancer, caution is advised when translating these values to other populations. Ideally, cutoff values for sarcopenia 
should be established within each specific patient population and BMI category. A much larger sample size would be required to undertake cutoff values analyses by gender and by Body Mass Index (BMI). It is important to realize that there has been mounting evidence on the clinical importance of BMI in the field of traumatology. An observational prospective study of Childs et al. shows an increased risk of infections, acute renal failure, length of ICU stay, hospital length of stay, and duration of mechanical ventilation in polytrauma patients with a BMI $>30$ [43]. In addition, our analyses suggest differences in prevalence of sarcopenia between different BMI ranges, with an increasing portion of sarcopenic trauma patients in higher BMI ranges. However, it is important to acknowledge that BMI does not distinguish between muscle and fat tissues. Increase in routinely obtained CT-scanning gives the opportunity to assess CT-based anthropometric parameters of fat in addition to muscle mass. A recent study of Poros et al. showed that CT-based assessment of abdominal fat is suitable in revealing pathologic body composition in trauma patients [44]. Abdominal fat measurements might add valuable information in relation to complications and mortality in trauma patients in future studies.

The current study was a pilot study, where a retrospective analysis of collected data was performed as a first step to elucidate the clinical impact of sarcopenia in trauma patients. This study has therefore limitations that have to be kept in mind in interpretation of the results. One of the limitations of this study is its retrospective nature. Because only data from patients with an abdominal CT were included in our analysis, there is a potential inclusion bias. Still, all cases were retrieved from a regional prospective trauma registry, thereby limiting the effect of potential selection bias. Another limitation is the heterogeneity of the study population. Traumatic events occur in any age group with different grades of severity. In order to limit the effect of heterogeneity, only patients with an ISS $\geq 16$ were included, and age-specific analysis was obtained regarding the prevalence of sarcopenia and its complications. Finally, only CT data were analyzed, and other markers of frailty such as functional and nutritional status were not included in our analysis.

In future studies, functional tests should, if possible, be included in the criteria for sarcopenia. Moreover, the cut-off values for skeletal mass index on CT measurements may require different cut-off points based upon reported outcome in this specific population.

\section{Conclusions}

The prevalence of sarcopenia in elderly polytrauma patients is high, reaching $85 \%$ in people over 80 years old. Our analysis also shows that sarcopenia is an independent predictor for 30-day mortality. Since abdominal CT scans are now almost routinely obtained in trauma patients, we advocate the measurement of skeletal mass measurement to detect decreased muscle mass early. Early identification of people at risk for sarcopenia will lead to early diagnosis and therapy, and more awareness will help to prevent additional loss of muscle mass during the admission after trauma.

Author Contributions: Conceptualization, R.C.S. and T.J.B.; data curation, M.A.-A.; formal analysis, R.C.S., M.P., and T.J.B.; methodology, K.W.R. and J.A.T.B.; supervision, K.W.R., M.P., J.A.T.B., and T.J.B.; writing-original draft, R.C.S., K.W.R., and M.A.-A.; writing—review and editing, M.P., T.J.B. and J.A.T.B. All authors have read and agreed to the published version of the manuscript.

Funding: This research received no external funding.

Acknowledgments: We acknowledge support by the Open Access Publication Funds of the Göttingen University.

Conflicts of Interest: The authors declare no conflicts of interest.

\section{References}

1. Cruz-Jentoft, A.J.; Bahat, G.; Bauer, J.; Boirie, Y.; Bruyère, O.; Cederholm, T.; Cooper, C.; Landi, F.; Rolland, Y.; Sayer, A.A.; et al. Sarcopenia: Revised European consensus on definition and diagnosis. Age Ageing 2018, 48 , 16-31. [CrossRef] [PubMed]

2. Cruz-Jentoft, A.J.; Baeyens, J.P.; Bauer, J.M.; Boirie, Y.; Cederholm, T.; Landi, F.; Martin, F.C.; Michel, J.-P.; Rolland, Y.; Schneider, S.M.; et al. Sarcopenia: European consensus on definition and diagnosis: Report 
of the European Working Group on Sarcopenia in Older People. Age Ageing 2010, 39, 412-423. [CrossRef] [PubMed]

3. Dodds, R.M.; Sayer, A.A. Sarcopenia, frailty and mortality: The evidence is growing. Age Ageing 2016, 45, 570-571. [CrossRef]

4. Marzetti, E.; Calvani, R.; Tosato, M.; Cesari, M.; Di Bari, M.; Cherubini, A.; Collamati, A.; D'Angelo, E.; Pahor, M.; Bernabei, R.; et al. Sarcopenia: An overview. Aging Clin. Exp. Res. 2017, 29, 11-17. [CrossRef] [PubMed]

5. Jones, S.E.; Maddocks, M.; Kon, S.S.; Canavan, J.L.; Nolan, C.M.; Clark, A.L.; Polkey, M.I.; Man, W.D.-C. Sarcopenia in COPD: Prevalence, clinical correlates and response to pulmonary rehabilitation. Thorax 2015, 70, 213-218. [CrossRef] [PubMed]

6. Yazar, T.; Yazar, H.O.; Zayimoğlu, E.; Çankaya, S. Incidence of sarcopenia and dynapenia according to stage in patients with idiopathic Parkinson's disease. Neurol. Sci. 2018, 39, 1415-1421. [CrossRef] [PubMed]

7. Joglekar, S.; Nau, P.N.; Mezhir, J.J. The impact of sarcopenia on survival and complications in surgical oncology: A review of the current literature. J.Surg.Oncol. 2015, 112, 503-509. [CrossRef]

8. Cruz-Jentoft, A.J.; Landi, F.; Topinková, E.; Michel, J.-P. Understanding sarcopenia as a geriatric syndrome. Curr. Opin. Clin. Nutr. Metab. Care 2010, 13,1-7. [CrossRef]

9. Lieffers, J.R.; Bathe, O.F.; Fassbender, K.; Winget, M.; Baracos, V.E. Sarcopenia is associated with postoperative infection and delayed recovery from colorectal cancer resection surgery. Br. J. Cancer 2012, 107, 931-936. [CrossRef] [PubMed]

10. Friedman, J.; Lussiez, A.; Sullivan, J.; Wang, S.C.; Englesbe, M.J. Implications of Sarcopenia in Major Surgery. Nutr. Clin. Pr. 2015, 30, 175-179. [CrossRef]

11. Dimitriou, R.; Calori, G.M.; Giannoudis, P.V. Polytrauma in the elderly: Specific considerations and current concepts of management. Eur. J. Trauma Emerg. Surg. 2011, 37, 539-548. [CrossRef]

12. Braun, B.; Holstein, J.; Fritz, T.; Veith, N.T.; Herath, S.; Mörsdorf, P.; Pohlemann, T. Polytrauma in the elderly: A review. EFORT Open Rev. 2016, 1, 146-151. [CrossRef] [PubMed]

13. Malekpour, M.; Bridgham, K.; Jaap, K.; Erwin, R.; Widom, K.; Rapp, M.; Leonard, D.; Baro, S.; Dove, J.; Hunsinger, M.; et al. The Effect of Sarcopenia on Outcomes in Geriatric Blunt Trauma. Am. Surg. 2017, 83, 1203-1208. [CrossRef] [PubMed]

14. Fairchild, B.; Webb, T.P.; Xiang, Q.; Tarima, S.; Brasel, K. Sarcopenia and frailty in elderly trauma patients. World J. Surg. 2015, 39, 373-379. [CrossRef] [PubMed]

15. DeAndrade, J.; Pedersen, M.; Garcia, L.; Nau, P. Sarcopenia is a risk factor for complications and an independent predictor of hospital length of stay in trauma patients. J. Surg. Res. 2018, 221, 161-166. [CrossRef] [PubMed]

16. Bhasin, S.; Travison, T.G.; Manini, T.M.; Patel, S.; Pencina, K.M.; Fielding, R.A.; Magaziner, J.M.; Newman, A.B.; Kiel, D.P.; Cooper, C.; et al. Sarcopenia Definition: The Position Statements of the Sarcopenia Definition and Outcomes Consortium. J. Am. Geriatr. Soc. 2020. [CrossRef] [PubMed]

17. Chen, L.-K.; Liu, L.-K.; Woo, J.; Assantachai, P.; Auyeung, T.-W.; Bahyah, K.S.; Chou, M.-Y.; Chen, L.-Y.; Hsu, P.-S.; Krairit, O.; et al. Sarcopenia in Asia: Consensus Report of the Asian Working Group for Sarcopenia. J. Am. Med Dir. Assoc. 2014, 15, 95-101. [CrossRef]

18. Prado, C.M.; Lieffers, J.R.; McCargar, L.J.; Reiman, T.; Sawyer, M.B.; Martin, L.; Baracos, V.E. Prevalence and clinical implications of sarcopenic obesity in patients with solid tumours of the respiratory and gastrointestinal tracts: A population-based study. Lancet Oncol. 2008, 9, 629-635. [CrossRef]

19. Reisinger, K.W.; Van Vugt, J.L.A.; Tegels, J.; Snijders, C.; Hulsewé, K.W.E.; Hoofwijk, A.G.; Stoot, J.; Von Meyenfeldt, M.F.; Beets, G.L.; Derikx, J.P.M.; et al. Functional Compromise Reflected by Sarcopenia, Frailty, and Nutritional Depletion Predicts Adverse Postoperative Outcome After Colorectal Cancer Surgery. Ann. Surg. 2015, 261, 345-352. [CrossRef]

20. Mitsiopoulos, N.; Baumgartner, R.N.; Heymsfield, S.B.; Lyons, W.; Gallagher, D.; Ross, R. Cadaver validation of skeletal muscle measurement by magnetic resonance imaging and computerized tomography. J. Appl. Physiol. 1998, 85, 115-122. [CrossRef]

21. Mourtzakis, M.; Prado, C.M.; Lieffers, J.R.; Reiman, T.; McCargar, L.J.; Baracos, V.E. A practical and precise approach to quantification of body composition in cancer patients using computed tomography images acquired during routine care. Appl. Physiol. Nutr. Metab. 2008, 33, 997-1006. [CrossRef]

22. Sattar, S.B.A.; Sharma, S. Bacterial Pneumonia; StatPearls Publishing: Tampa/St. Petersburg, FL, USA, 2019. 
23. Hooton, T.M.; Stamm, W.E. DIAGNOSIS AND TREATMENT OF UNCOMPLICATED URINARY TRACT INFECTION. Infect. Dis. Clin. North Am. 1997, 11, 551-581. [CrossRef]

24. Inouye, S.K. Delirium in Older Persons. N. Engl. J. Med. 2006, 354, 1157-1165. [CrossRef] [PubMed]

25. Pichard, C.; Kyle, U.G.; Morabia, A.; Perrier, A.; Vermeulen, B.; Unger, P. Nutritional assessment: Lean body mass depletion at hospital admission is associated with an increased length of stay. Am. J. Clin. Nutr. 2004, 79, 613-618. [CrossRef]

26. Cosquéric, G.; Sebag, A.; Ducolombier, C.; Thomas, C.; Piette, F.; Weill-Engerer, S. Sarcopenia is predictive of nosocomial infection in care of the elderly. Br. J. Nutr. 2006, 96, 895-901. [CrossRef] [PubMed]

27. Prado, C.M.; Baracos, V.E.; McCargar, L.J.; Reiman, T.; Mourtzakis, M.; Tonkin, K.; Mackey, J.R.; Koski, S.; Pituskin, E.; Sawyer, M.B. Sarcopenia as a Determinant of Chemotherapy Toxicity and Time to Tumor Progression in Metastatic Breast Cancer Patients Receiving Capecitabine Treatment. Clin. Cancer Res. 2009, 15, 2920-2926. [CrossRef]

28. Antoun, S.; Baracos, V.E.; Birdsell, L.; Escudier, B.; Sawyer, M.B. Low body mass index and sarcopenia associated with dose-limiting toxicity of sorafenib in patients with renal cell carcinoma. Ann. Oncol. 2010, 21, 1594-1598. [CrossRef]

29. Van Vledder, M.G.; Levolger, S.; Ayez, N.; Verhoef, C.; Tran, T.C.K.; Ijzermans, J.N.M. Body composition and outcome in patients undergoing resection of colorectal liver metastases. BJS 2012, 99, 550-557. [CrossRef]

30. Cruz-Jentoft, A.J.; Landi, F.; Schneider, S.M.; Zúñiga, C.; Arai, H.; Boirie, Y.; Chen, L.-K.; Fielding, R.A.; Martin, F.C.; Michel, J.-P.; et al. Prevalence of and interventions for sarcopenia in ageing adults: A systematic review. Report of the International Sarcopenia Initiative (EWGSOP and IWGS). Age Ageing 2014, 43, 748-759. [CrossRef]

31. Vergara-Fernandez, O.; Trejo-Avila, M.; Salgado-Nesme, N. Sarcopenia in patients with colorectal cancer: A comprehensive review. World J. Clin. Cases 2020, 8, 1188-1202. [CrossRef]

32. Morley, J.E. Sarcopenia: Diagnosis and treatment. J. Nutr. Heal. Aging 2008, 12, 452-456. [CrossRef]

33. Von Haehling, S.; Anker, S.D. Cachexia as a major underestimated and unmet medical need: Facts and numbers. J. Cachex-Sarcopenia Muscle 2010, 1, 1-5. [CrossRef] [PubMed]

34. Von Haehling, S.; Morley, J.E.; Anker, S.D. An overview of sarcopenia: Facts and numbers on prevalence and clinical impact. J. Cachex-Sarcopenia Muscle 2010, 1, 129-133. [CrossRef] [PubMed]

35. Kim, J.-K.; Choi, S.R.; Choi, M.J.; Kim, S.G.; Lee, Y.K.; Noh, J.W.; Kim, H.J.; Song, Y.R. Prevalence of and factors associated with sarcopenia in elderly patients with end-stage renal disease. Clin. Nutr. 2014, 33, 64-68. [CrossRef]

36. Villaseñor, A.; Ballard-Barbash, R.; Baumgartner, K.; Baumgartner, R.; Bernstein, L.; McTiernan, A.; Neuhouser, M.L. Prevalence and prognostic effect of sarcopenia in breast cancer survivors: The HEAL Study. J. Cancer Surviv. 2012, 6, 398-406. [CrossRef]

37. Yang, M.; Liu, Y.; Zuo, Y.; Tang, H. Sarcopenia for predicting falls and hospitalization in community-dwelling older adults: EWGSOP versus EWGSOP2. Sci. Rep. 2019, 9, 1-8. [CrossRef]

38. Wall, B.T.; Dirks, M.L.; Van Loon, L. Skeletal muscle atrophy during short-term disuse: Implications for age-related sarcopenia. Ageing Res. Rev. 2013, 12, 898-906. [CrossRef]

39. Brown, J.C.; Harhay, M.O.; Harhay, M.N. Sarcopenia and mortality among a population-based sample of community-dwelling older adults. J. Cachex- Sarcopenia Muscle 2015, 7, 290-298. [CrossRef] [PubMed]

40. Liu, P.; Hao, Q.; Hai, S.; Wang, H.; Cao, L.; Dong, B. Sarcopenia as a predictor of all-cause mortality among community-dwelling older people: A systematic review and meta-analysis. Maturitas 2017, 103, 16-22. [CrossRef]

41. Leeper, C.M.; Lin, E.; Hoffman, M.; Fombona, A.; Zhou, T.; Kutcher, M.; Rosengart, M.; Watson, G.; Billiar, T.; Peitzman, A.; et al. Computed Tomography Abbreviated Assessment of Sarcopenia Following Trauma: The CAAST Measurement Predicts 6-month Mortality in Older Adult Trauma Patients. J. Trauma Acute Care Surg. 2016, 80, 805-811. [CrossRef] 
42. Sierink, J.C.; Treskes, K.; Edwards, M.J.R.; Beuker, B.J.A.; Hartog, D.D.; Hohmann, J.; Dijkgraaf, M.G.W.; Luitse, J.S.K.; Beenen, L.F.M.; Hollmann, M.W.; et al. Immediate total-body CT scanning versus conventional imaging and selective CT scanning in patients with severe trauma (REACT-2): A randomised controlled trial. Lancet 2016, 388, 673-683. [CrossRef]

43. Childs, B.R.; Nahm, N.J.; Dolenc, A.J.; Vallier, H.A. Obesity Is Associated With More Complications and Longer Hospital Stays After Orthopaedic Trauma. J. Orthop. Trauma 2015, 29, 504-509. [CrossRef]

44. Poros, B.; Irlbeck, T.; Probst, P.; Volkmann, A.; Paprottka, P.; Böcker, W.; Irlbeck, M.; Weig, T. Impact of pathologic body composition assessed by CT-based anthropometric measurements in adult patients with multiple trauma: A retrospective analysis. Eur. J. Trauma Emerg. Surg. 2019, 2019, 1-15. [CrossRef]

(C) 2020 by the authors. Licensee MDPI, Basel, Switzerland. This article is an open access article distributed under the terms and conditions of the Creative Commons Attribution (CC BY) license (http://creativecommons.org/licenses/by/4.0/). 